\title{
Investigations on the Dissimilar Metal Joints Capability between Aluminum Alloy and Steel under CMT Welding
}

\author{
Chen Chen ${ }^{1}$, Chenhao $\mathrm{Gao}^{2}$ and Yanfeng Xing ${ }^{2}$ \\ ${ }^{1}$ Department of Scientific Research, Shanghai University of Engineering Science, Shanghai, China \\ ${ }^{2}$ Automotive Engineering College, Shanghai University of Engineering Science, Shanghai, China
}

\begin{abstract}
Sustainable lightweight vehicle design has becoming a key trend in the future. A new way to join aluminum alloys and steel sheet. Cold metal transfer (CMT) welding of thin sheet metal products. Determination of equilibrium wire-feed-speeds welding-speeds and arc length. Seam formation and microstructure of CMT were researched. Not only that, but optimum welding parameters were analyzed. Study of welding joint microstructure of compound layer on welding joint. Comparing the steel side of welding seam. The aluminum alloy siding grain size was larger. After tensile test, joint was fractured on the aluminum alloy side. Warp deformation occurred on aluminum side. Displacement of warp deformation became larger along with the increase of welding current. The results reviewed in this article indicate that the aluminum alloy fractured is more preferable to steel. CMT welding has found applications in automobile industries, defence sectors and power plants as a method of additive manufacturing.
\end{abstract}

\section{Introduction}

Sustainable lightweight vehicle design has becoming a key trend in the future. It has the advantages of energy-saving, emission-reduction and increase of dynamic and safety performance. Since aluminum alloys have many strong points like low density, high specific strength, corrosion resistance and good damping capacity. Aluminum alloys are widely used in automobile industry for the purpose of reduction in the vehicle weight ${ }^{[1]}$. Z Silvayeh found that aluminum alloy car-body have advantages of lightweight and strength ${ }^{[2]}$. However, Meyghani $B$ found that aluminum alloys welding have deformation problems ${ }^{[3]}$. Deng established a thermal elasto-plastic model based on ABAQUS finite element software ${ }^{[4]}$. Simplified models can be used to predict residual stress of dissimilar metal pipe welding joint. Chin-Hyung did the finite element analysis of welding temperature between carbon steel and stainless steel tilted to carbon steel side near the lowest heat generation ${ }^{[5]}$. Temperature distribution in the process of welding is dissimilar metal have been inconsistent. Zhou put forward inherent strain method and analyzed welding deformation of alloys ${ }^{[6]}$. Welding size quality is difficult to control, so it is important to research the property of welding joint. Uday took different methods to research plastic deformation of welding joint and analyzed its micro-structure ${ }^{[7]}$.

However, it is difficult to obtain a sound joint to aluminum alloy and steel in different melting temperature and thermal expansion. Thus, it is important to find out how to mix aluminum alloy and steel together. $\mathrm{H}$ Lei found that CMT increases the strength had positive effect on maintaining tensile strength, corrosion resistance, and fatigue strength of $\mathrm{Al} / \mathrm{Steel}{ }^{[8]}$.E Taban found out that the thickness of intermetallic compound between welding filler material and steel (base metal) was so small that could only be observed in the micron level ${ }^{[9]}$. In the process of CMT welding, component and thickness of intermetallic compound on interface reaction zone presented regular distribution under different welding parameters ${ }^{[10]}$.

In this paper, the experiment process is referred to the theory put forward by Xinmin Lai that both product design and process planning control are indispensable ${ }^{[11]}$. This theory consisted with the physical model building of aluminium-steel mixed joint sheet, the study on performance of digital metal joint with detailed design and simulation verification. Related to all aspects on the design of $\mathrm{Al} / \mathrm{Steel}$ dissimilar metal welding process were researched to make sure that the design of welding parameter was under the same condition, to ensure the consistency and continuity of welding joint quality was ensured. Moreover, micro-structure analysis and SYSWELD prediction is coordinated to the design of this experiment and simulation. The data of different welding parameters which greatly affected the weld appearance and deformation are selected by orthogonal experiment. Double elliptical heat source is selected to establish $\mathrm{Al} /$ Steel sheet welding seam model.

The research process in this paper conclude a practical control of welding and simulation verification. Welding joint with good appearance and high quality is acquired by controlling welding parameters. Micro-structure of welding joint is observed by metallographic analysis method which research the effect on mechanical property 
of welding seam. 3D finite element simulation and coordination and parallel design of the process manufacturing are done to forecast deformation after welding. The property of welding joint for $\mathrm{Al} / \mathrm{Steel}$ dissimilar metal sheet by CMT welding technology is explored.

\section{Experiment material and methods}

The base materials are 6061-T6 aluminum alloy and Q235 zinc-coated steel sheet. The dimension of each sheet is $50 \mathrm{~mm} \times 150 \mathrm{~mm} \times 1 \mathrm{~mm}$, cut by wire cutting machine. CMT is used to join the dissimilar metals. Aluminum alloy sheet is polished by sandpaper to remove oxide film on its surface, avoiding the formation of welding defects due to oxide film. Steel surface is cleared to remove the stain and oil by acetone solution. Two pieces of metal sheet should be welded as soon as possible after cleaning to avoid adverse effects due to oxide formed on surface of metal sheet. Considering the difference of melting point and thermal conductivity between aluminum and steel, during the welding, the Al sheet is on the upper layer, and the steel sheet is on the lower layer. The length of lap is $10 \mathrm{~mm}$.

The test is performed with the welding equipment. They are a welding machine modeled in CMT-TPS400 and an industrial robot KUKA, as shown in Fig. 1. The CMT welding system is applied in the test. Welding voltage, welding current and wire feeding speeds are adjusted by changing one parameter to obtain different welding parameters. The distance between welding torch muzzle and weldment is $12 \mathrm{~mm}$. Dry extension of welding wire is $10 \mathrm{~mm}$. The flow of shielding gas is $15 \mathrm{~L} / \mathrm{min}$. For the purpose of making it easy to melt and spread welding wire, included angle between welding torch and welding direction is $45^{\circ}$.
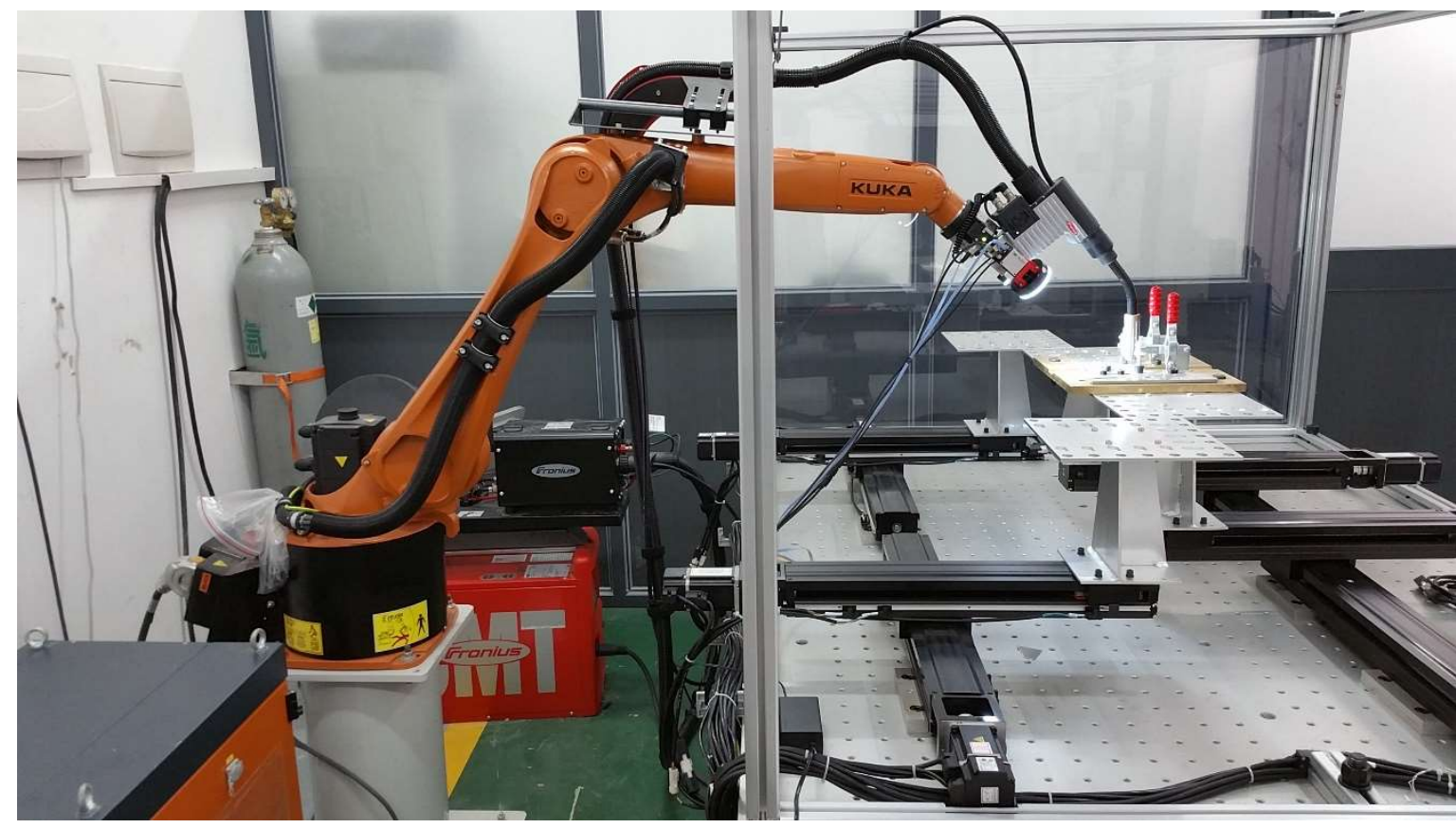

Figure 1. Welding equipment.

Welding parameters have an important effect on property of welding joint. Welding joint with high quality which met requirements of this experiment can be acquired by observing weld appearance under different welding parameters. Then the welding seam is cut and polished, the sample is soaked into Nital Alcohol solution to observe micro-structure. The tensile test of welding seam is carried out to explore the mechanical properties of welding joint. SYSWELD software is used to simulate deformation during welding process, then deformation displacement is valued to validate the prediction of welding deformation by SYSWELD simulation.

\section{Result and discussion}

\subsection{Analysis of welding parameter affecting Al/Steel welding seam formation}

Three important welding parameters are selected to research weld appearance and welding deformation. By changing wire feeding speeds, welding speeds and arc length corrections, the influence of these three parameters on macroscopic morphology of welding seam formation is observed. The optimal welding parameters are obtained according to the best weld appearance and minimum welding deformation.

As shown in Fig.2 (a), when welding speed is $0.65 \mathrm{~m} / \mathrm{min}$, arc length correction is $5 \%$, the sample with wiring speed of $4.2 \mathrm{~m} / \mathrm{min}$ has a minimum longitudinal deformation displacement. As shown in Fig.2 (b), when wiring speed is $3.8 \mathrm{~m} / \mathrm{min}$, welding current is $66 \mathrm{~A}$, the sample with welding speed of $0.6 \mathrm{~m} / \mathrm{min}$ has a minimum longitudinal deformation displacement. As shown in Fig.2 (c), when wiring speed is $3.8 \mathrm{~m} / \mathrm{min}$, welding speed is $0.65 \mathrm{~m} / \mathrm{min}$, the sample with arc length correction of $5 \%$ has a minimum longitudinal deformation displacement. 
Under these three situations, longitudinal deformation displacement of aluminum sheet side is larger than that on the steel sheet side. Compared with the deformation displacement, optimal welding parameters are in accordance with the conclusion above

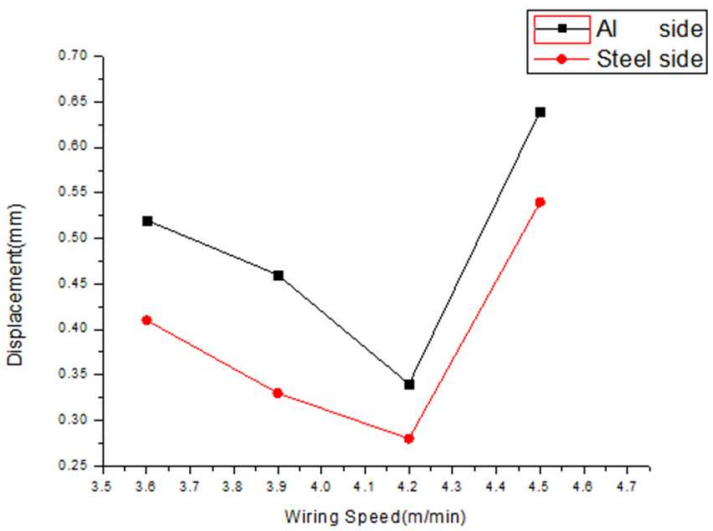

(a) Wire feeding speed

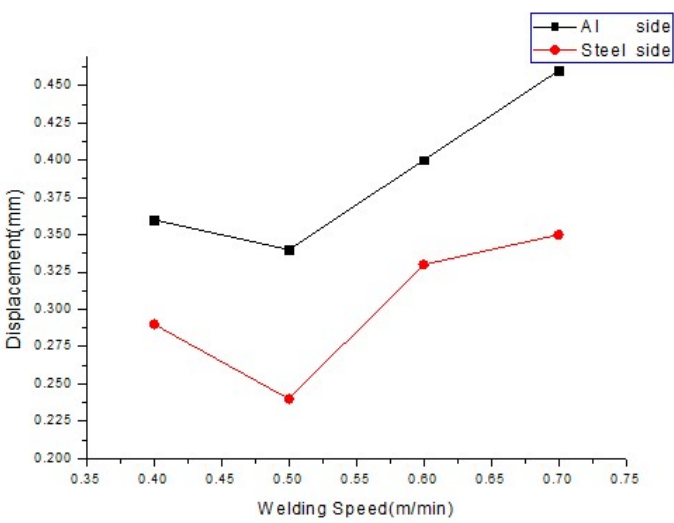

(b) Welding speeds

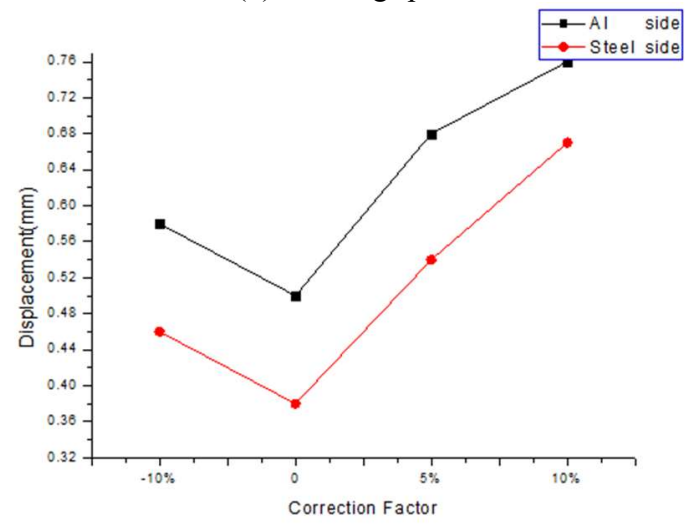

(c) Arc length corrections

Figure 2. Effect of different welding parameter on longitudinal deformation displacement.

\subsection{Tensile test of welding joint}

According tensile test measure to test tensile strength and quality of welding joint. The tensile sample is shown in Fig.3 (a). At room temperature, the tensile test is carried out on the mechanical test machine at the speed of $1 \mathrm{~mm} / \mathrm{min}$. The relationship between tensile displacement and test force is shown in Fig. 3 (b). At the beginning of tensile, tensile displacement increased along with the increasing of force load rapidly. When the load reached $3400 \mathrm{~N}$, welding joint of $\mathrm{Al} / \mathrm{Steel}$ fractured, load fore decreased rapidly. It is observed that the fracture position of welding joint is located on the heat affected zone of aluminum alloy side. The thin distribution of intermetallic compound, grain with smaller size and existence of zinc rich region on the aluminum alloy side are all the reasons for reducing the mechanical properties of welding joint. In study of $\mathrm{Al} / \mathrm{Steel}$ dissimilar metal welding, the main form of welding is melting brazing welding, because of melting point between aluminum alloy and steel is different. The upper layer of aluminum sheet is melting welding and the lower layer steel sheet is brazing welding, so that aluminum sheet and steel sheet are connected.

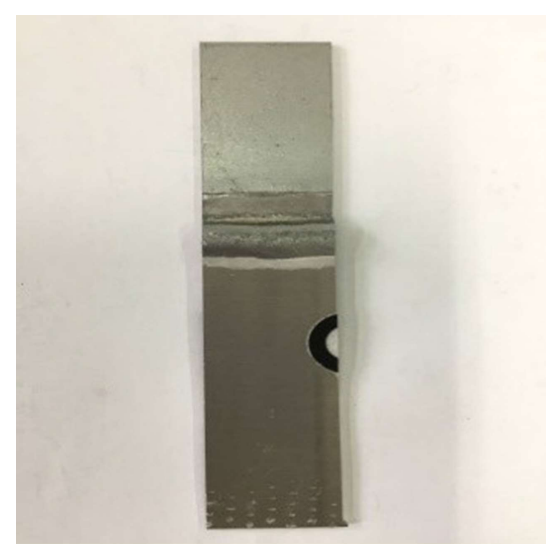

(a) Tensile sample

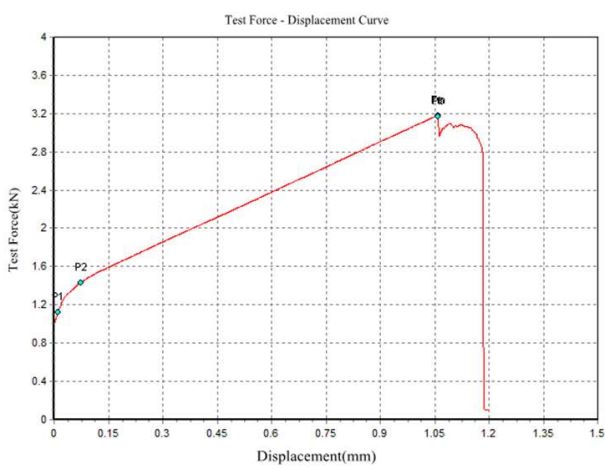

(b) Load-displacement curve

Figure 3. Tensile test of welding joint.

\section{Conclusions}

(1) In the dissimilar welding between aluminum and steel, welding seam with good-looking and high quality can be obtained by optimizing welding parameters. With the wire feeding speed of $4.2 \mathrm{~m} / \mathrm{min}$, welding speed of $0.6 \mathrm{~m} / \mathrm{min}$ and arc length correction of $5 \%$, the best quality of welding seam formation is acquired.

(2) There is a little difference shown on the weld appearance under different wire feeding speed, welding speed and arc length correction. Welding seam becomes wider along with the increase of wire feeding speed. The width of welding seam decreases along with the increase of welding speed. Weld width becomes wider along with the increase of arc length correction factor. 
(3) The micro-structure of welding joint show that the size of grains on aluminum alloy side is larger than that on steel side. The zinc-rich zone is located on aluminum alloy side of the welding toe. Welding defects such as gas holes and low melt shrinkage holes mainly occurrs on the aluminum alloy side. These adverse factors results that mechanical properties on aluminum alloy side are poorer than that on steel side. Welding joint fractured on aluminum alloy side after tensile test.

(4) It was found that the large displacement distance of the sheet parts appeared on the side of the aluminum sheet during the welding process. Due to the greater thermal conductivity of aluminum alloy, the shrinkage of the aluminum sheet was larger than that of the steel sheet. Therefore, the aluminum alloy was subjected to larger welding deformation and had a obvious warp deformation. Displacement of warp deformation became larger along with the increase of welding current.

\section{References}

1. Lou M. J MANUF SCI E-T ASME. 135 (2013).

2. Silvayeh Z, Vallant R, Sommitsch C. METALL MATER TRANS A, 48, 11 (2017).

3. Meyghani B, Awang M B, Emamian S S. Metals Open Access Metallurgy Journal, 7, 10 (2017).

4. Deng D, Shoichi Kiyoshimab, Kazuo Ogawa. NUCL ENG DES, 241 (2011).

5. Lee $\mathrm{C} \mathrm{H}$, Chang K H. APPL THERM ENG, 45-46, (2012).

6. Zhou J, Chang BH, Zhang Y. Welding technology, 39 (2010).

7. M. B. Uday, M. N. Ahmad-Fauzi. MECH MATER, 10, 91 (2015).

8. Lei H, Li Y B, Carlson B E. J MANUF SCI E-T ASME, 7, 138 (2015).

9. Taban E, Gould J E, Lippold J C. MATER DESIGN, 5, 31 (2010)

10. Kumar N P, Vendan S A, Siva N. J ALLOY COMPD, 658 (2016).

11. Yi P, Du X, Kan Y. INT J HYDROGEN ENERG, 14, 40 (2015). 